\title{
From shell work to shell art: Koori women creating knowledge and value on the South Coast of NSW'
}

\author{
By Daphne Nash
}

\begin{abstract}
Daphne Nash completed her $\mathrm{PhD}$ in Interdisciplinary Cross-cultural Research at the Research School of Humanities, Australian National University in 2009. Her thesis is entitled 'Transforming knowledge: Indigenous Knowledge and culture workers on the south coast of NSW'. Daphne has also worked as a teacher and more recently as a research consultant on educational resources relating to Indigenous cultural heritage.
\end{abstract}

\begin{abstract}
For many years the shell art of Aboriginal women on the South Coast of New South Wales has been an icon of Aboriginal people's survival in that region. It is on the record since the 1880s that Koori women have made shell work objects to sell to tourists. This practice is undergoing a revival, and recognition of shell art is increasing particularly through the making of Sydney Harbour Bridges and miniature shoes. As the art work of Indigenous people, shell art is increasingly entering into the art market. When its cultural connections are understood, shell art is no longer dismissed as "tourist art". What forces are operating and how does shell art mean?
\end{abstract}

This paper explores the processes of cultural revitalisation and value creation, testing the categorisation of shell art as either Aboriginal or Western, traditional or contemporary, art or craft. In many ways these binaries are not sustainable as contemporary Koori artists connect with their cultural heritage in new ways. It examines the explicit and implicit knowledge contained in the shelled objects, emphasising the complexity of contemporary cross-cultural exchanges and their influences on modes of knowledge production. The value of shell art is transforming through the engagement of Kooris with the art market and other cultural institutions. Moreover, Koori women are finding agency in this continuing cultural practice.

\section{Introduction}

Ornamental shell work is found in many parts of the world where 'delicate and elaborate designs are created using shells in profusion' (Thomas 2007: 135). On

1 Koori (also spelt Koorie) is the term used by Aboriginal people and now accepted in Australian English to refer to Aboriginal people from much of south-eastern Australia, particularly Victoria and most of New South Wales. 
the South Coast of New South Wales (Plate 1), women from the Koori community have a particular history associated with this activity. As the historical record shows, women made shell baskets at La Perouse to sell in Sydney in the 1880s (Nugent 2005: 49). Since then, Koori women in many places on the South Coast have maintained and developed this practice. Today, shell work or shell art is an active site of knowledge production and value creation.

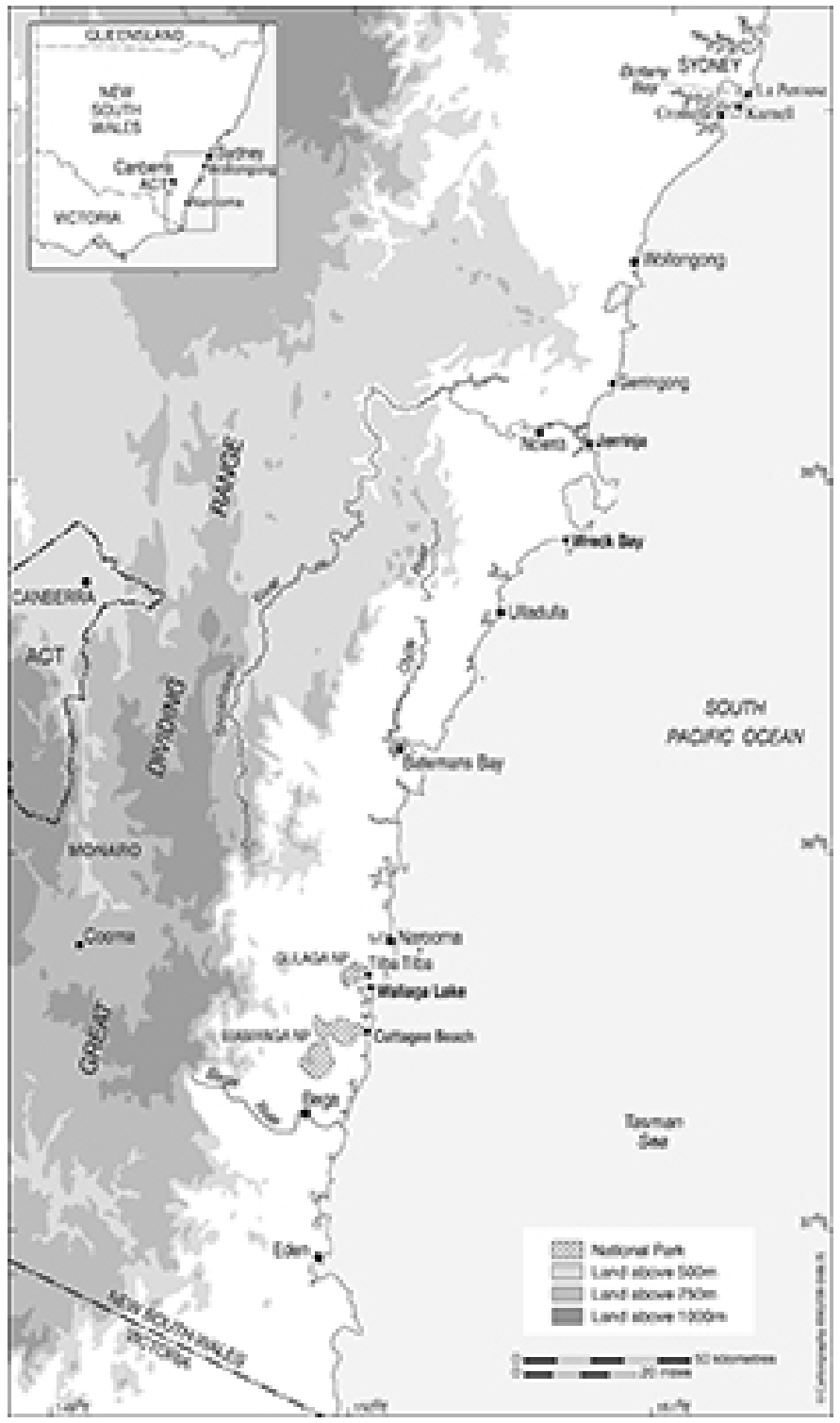

Plate 1: South Coast of New South Wales. For the purposes of this study, the 'South Coast' is the coastal region from Sydney to the Victorian border and inland to the Great Dividing Range. 
This paper presents a case study of shell art as a cultural act. Shell art has become a 'crucial space for negotiation' (Phillips 1999: 50), however narrow, of a cross-cultural history of people and place on the South Coast. Two important questions guide this discussion: how is shell art valued and how does it mean? My analysis draws out many historical and cultural associations of this particular Indigenous women's art practice culminating in discussion of a recent shell art installation at the Museum of Contemporary Art (MCA) in Sydney. Such new interpretations reveal how shell art can be an expression of deep personal and cultural loss. From its cross-cultural origins and through continued practice, shell artists express their political resistance as well as cultural knowledge through the exhibition and sale of their work.

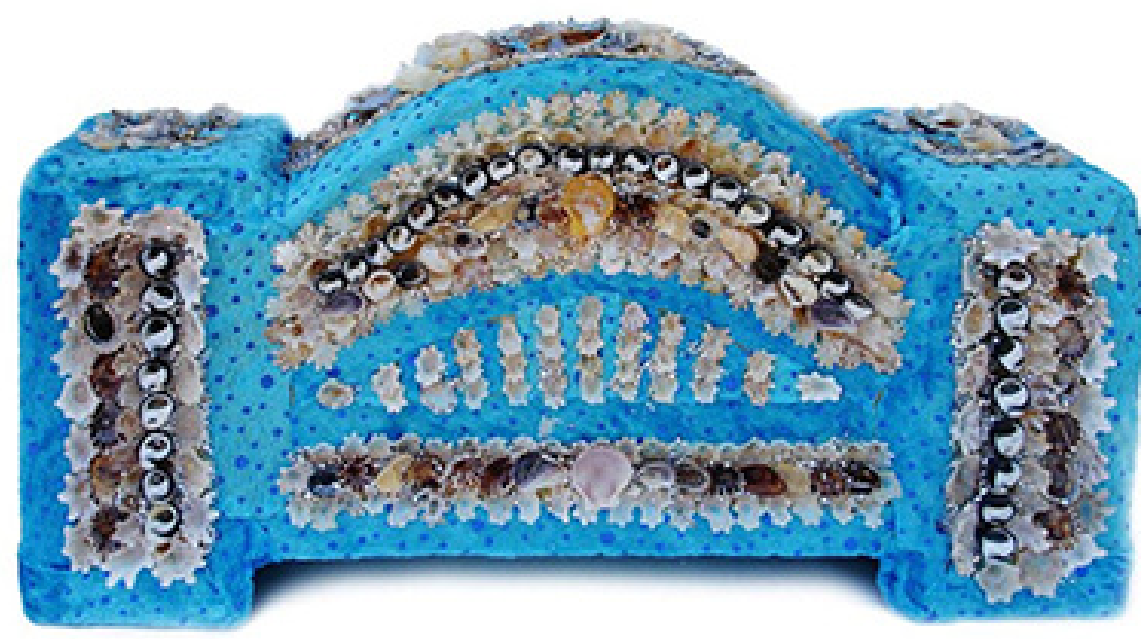

Plate 2: Esme Timbery, Harbour Bridge, 2006 , shells, fabric and cardboard, $30 \times 15$ x $7 \mathrm{~cm}$. A similar work to her prize winning artwork of the same name. Private collection.

Photograph: Daphne Nash.

Museums and art galleries in the region have collected La Perouse women's shell art over several decades. ${ }^{2}$ In the last decade particularly, Indigenous curators such as Allas (2006) and Mundine (2008) have promoted shell artists in exhibitions and written about their work. In 2005, a shell artist, Esme Timbery won the inaugural NSW Parliament Indigenous Art Prize (Parliament of New South Wales 2005) for a decorated model of the Sydney Harbour Bridge (Plate 2) and in 2008, a shell art installation featured at an MCA exhibition. This recent inclusion of shell art into the world of fine art as collectible objects represents a

2 The Powerhouse Museum in Sydney acquired several La Perouse shell objects from the 1950s and 1960s, and commissioned works from women at La Perouse in 1986. At http://www. powerhousemuseum.com (accessed 20/3/2010). The National Gallery of Australia acquired the late Sarah Cruse's (1910-1996) shell art in 2005. At http://nga.gov.au (accessed 20/3/2010). The National Museum of Australia collected shell art ('baby shoes' possibly from the 1950s and 3 harbour bridges) from La Perouse in 2007. At http://www.nma.gov.au/ (accessed 20/3/2010). 
significant shift whereby cultural institutions are creating space for objects often categorised as kitsch or tourist art. While recognising the various categories within art, this paper moves beyond an aesthetic or visual critique to explore the process of Indigenous knowledge transmission and the cultural meaning of shell art today. As this case study of shell art demonstrates, the objects may operate as tourist art or commodities at times but the art market is not the main motivation for the makers. Indeed, the Aboriginal women carefully modulate their productivity in order to maintain control of their knowledge and creativity.

\section{Indigenous and European connections}

Historically, shells were a part of the material culture of south-eastern Aboriginal groups including those on the South Coast of NSW. In 1826, a missionary met people near Bateman's Bay with whom he traded, receiving gifts from the women including kangaroo teeth fastened to string made from possum fur with gum, shells and red ochre (Harper cited in Organ 1990: 141). A few decades later, the artist Louisa Atkinson (1854) recorded the use of multiple strand necklaces, made from segments of sedge threaded on string, and kangaroo teeth decoration on hair but she does not refer to any shell necklaces. In the late nineteenth century, however, an anthropological observer, Mathews (1896: 342), described the 'yanniwa' (women who were guardians of novices in initiation ceremonies) in the Shoalhaven region who 'wear strings of shells' among other adornments. Without further evidence, the extent to which the women on the South Coast were continuing a cultural practice of shell necklace-making is uncertain. Nevertheless, the practice continued in the twentieth century.

There may have been connections between other Indigenous and outside practices. Julie Freeman of Wreck Bay has a necklace made by her grandmother Rose Ardler in the 1920s from rice or rye shells threaded onto cotton and it is the 'same length as Tasmanian necklaces' (Wells 2003: 19). Any further connection with Tasmanian practices, however, needs further investigation. At La Perouse, 'women continued to make the occasional shell necklace using pinkies, starries and beachies' (Wells 2003:19). ${ }^{3}$ These necklaces, like some other shelled objects, may have been a response to the fashions of non-Indigenous women of the time.

On the South Coast, the Aboriginal women near Sydney were the first to use shells to decorate baskets for sale. In the 1880s, their shelled 'baskets were mainly sold to white suburban women' at stalls on Circular Quay and in other suburbs, beginning 'the transformation of shell art from Victorian-era curios to a Sydney souvenir' (Nugent 2005: 81). Local representatives of missionary groups in NSW, such as the Aboriginal Inland Mission worked in the La Perouse

3 Many of the shells used by Koori women are common small marine invertebrates, such as 'starries' (Scutellastra chapmani) and 'beachies' (Bankivia fasciata). Shell identification following Beechey (2009). 
Aboriginal community in Sydney and many Aboriginal people became involved in their work. They are credited with teaching the Aboriginal women how to do shell work and other marketable skills. In later years, especially the 1920s and 1930s, tourists came to the Aboriginal art and craft stall at The Loop at La Perouse, the terminus of the tramline from Sydney. Over the years, the women themselves increased the range of shell products as they took control of,production and the objects continued to sell. It appears that the women began with baskets and expanded to include other objects as they do today, such as small boxes, , picture frames and little shoes (Plate 3).

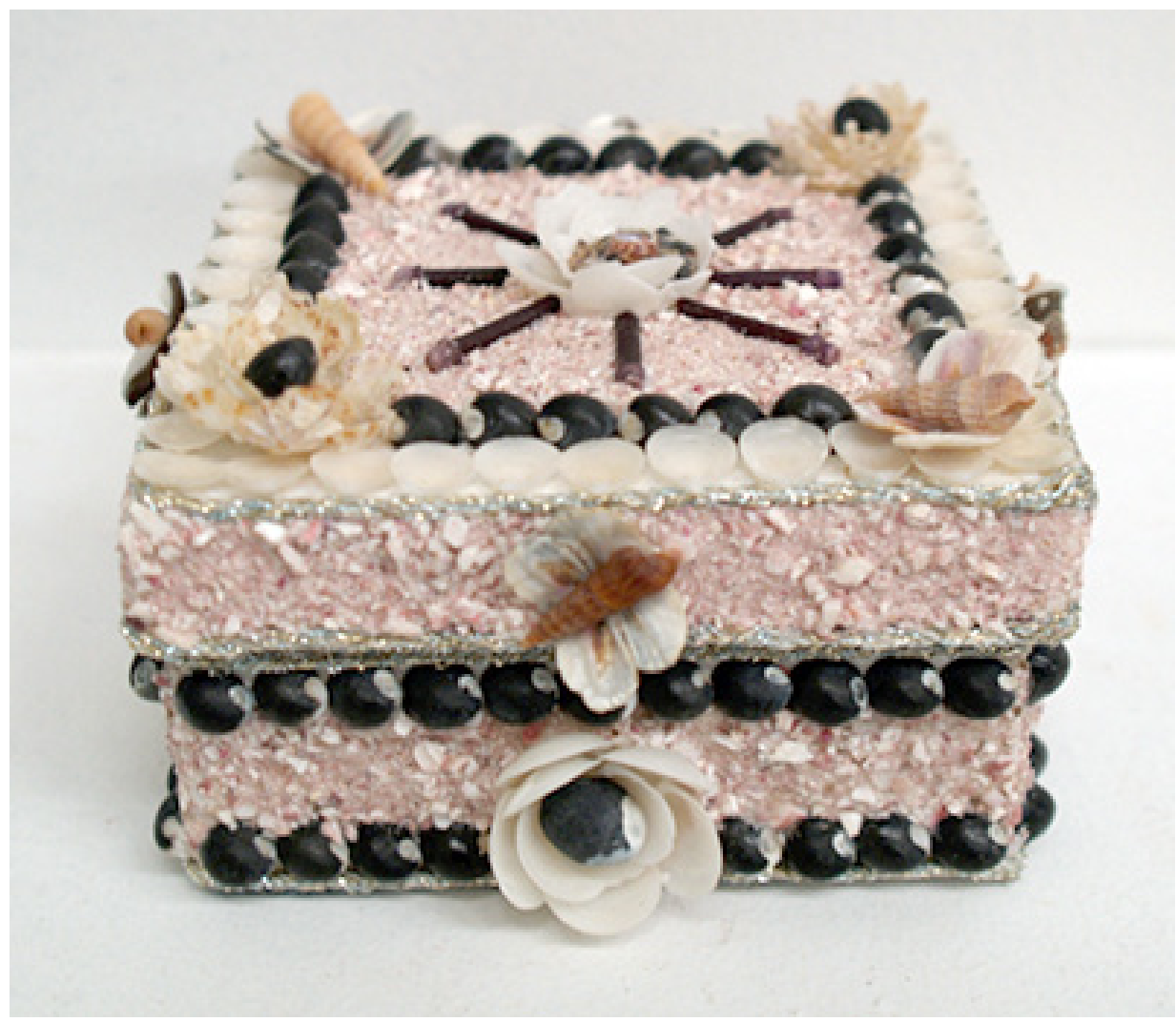

Plate 3: Suzanne Stewart, Jewellery Box, 2009, shells, fabric and cardboard. Collection of the artist.

Photograph: Kelli Ryan.

As for other colonised and Indigenous people, an understanding of tourist art and souvenirs must make reference to the 'implied texts' of the products. As Phillips (1999: argues for native Canadian women of the colonial period, their embroidered objects link them to notions of femininity through older associations with women's crafts, such as embroidery, and through newer ones 'to the homecrafts of "civilized" Victorian housewives'. Similarly, the occupation of handcraft including shell art was meant to be a step towards assimilation of Australian Aboriginal women while allowing a certain amount of autonomy. 
Mission and government authorities at the time had little awareness of 'women's economic and social roles in pre-invasion societies' (Goodall 1995:75) and sought to retrain them in the ways of Europeans to make them suitable workers and mothers. While this is the social and historical context for the beginnings of shell art, other hitherto neglected issues of cultural meaning also need to be explored.

What was the appeal of shell art and why did it sell? Anecdotally it seems that mostly non-Aboriginal women purchased the objects. Were they acknowledging a common aesthetic sense or possibly satisfying a desire for the 'exotic'? In its early years as tourist art, shell art was popular outside Australia too. In 1910, the Australian Aborigines Advocate reported that an exhibition of Queen Emma Timbery's renowned work 'was almost fought for' in London (Vanni 2000: 410). Indeed, the positive reception by the non-Indigenous consumer of shell art in colonial Australia follows on from the history of shell use in Europe (and America).

In eighteenth century England, ornamental shell work became popular in a variety of forms: in architecture, including house and garden decoration, ${ }^{4}$ combining art and botany (e.g. replicas of flowers, etc were displayed under glass), and, as well-to-do ladies' handcraft. As it does today, the work varied in its quality and aesthetics. By the early twentieth century 'the market for mass-produced ornaments' made 'cheap mementos' available all over the world and so 'the tradition of home-crafted decorative shell pieces slowly died away' (Thomas 2007: 140-141). Against the background of these European trends, the Koori women's hand-crafted objects had ready appeal for Australian women.'It is unclear, however, how much these trends influenced Aboriginal women's shell work. The aesthetics and meaning of the objects for the Aboriginal women have a different context, as this case study demonstrates.

\section{Kitsch, miniatures and the souvenir}

Like many Indigenous art objects sold to tourists, shell art can be labeled as kitsch. The appeal of shell art may relate to its kitsch appearance but not primarily to the accepted association of kitsch with poorly made or imitative work that is low down on the hierarchy of aesthetics. On the contrary, as Binkley

4 Two iconic examples from opposite ends of the eighteenth century point to the popularity of shell work in that era. Alexander Pope, the early eighteenth century English poet and writer had an elaborate shell grotto in his garden in Twickenham that indicated a revival in England at the time (Willson 1998: 31). In the late eighteenth century, Jane and Mary Parminter who trained as architects, designed much of their interior house furnishings at A-la-Ronde in Exmouth, Devon, 'using mosaic shell work and feather patterns favoured by 18th-century lady amateurs' (Walker 1986: 14). The National Trust now owns and exhibits the house.

5 Men also bought shell objects: 'One of their [La Perouse Aboriginal people] biggest markets was American servicemen in Australia during the Second World War' (Nugent cited at http://www. nma.gov.au/collections/shell_work_sydney_harbour_bridge/ (accessed 21/3/2010). Historically, the sale of shell work in other parts of the world has been linked with sailors who bought gifts for their valentines (Thomas 2007:140). 
(2000: 141) argues, kitsch is not a failed attempt at originality 'but instead it expresses a taste for derivation, imitation and a faithfulness to the tried and true'. In the case of shell art as a souvenir of white women's visits to La Perouse in the 1920s, the shelled object is a connection to the past and to feelings of nostalgia. Rather than sentimentalising Aboriginal people, the narrative of the experience is sentimentalised. As Stewart (1993: 35) suggests, the souvenir relates more to the moment of purchase for the tourist than to the makers.

Others have argued that the purchase and the act of taking the object into the home is a way in which non-Indigenous people appropriated the exotic souvenir (Moore 2005: 206). ${ }^{6}$ The possession of an exotic object offers access to another world, but which aspects of that world are relevant to shell art? It is the complex relationship between kitsch and miniature forms from the artists' perspectives that is highly significant for understanding shell art today. 'Most kitsch art objects convey a kind of deliberate and highly constructed innocence' (Sturken 2007: 21) and the miniature form has associated links to 'nostalgic views of childhood and history' (Stewart 1993: 69). Together these attributes present strong visual signs for interpretation of Koori women's shelled objects, especially the popular little shell shoes (Plate 4). Further analysis here requires some background discussion of the developing local cultural and historical context of shell art practice.

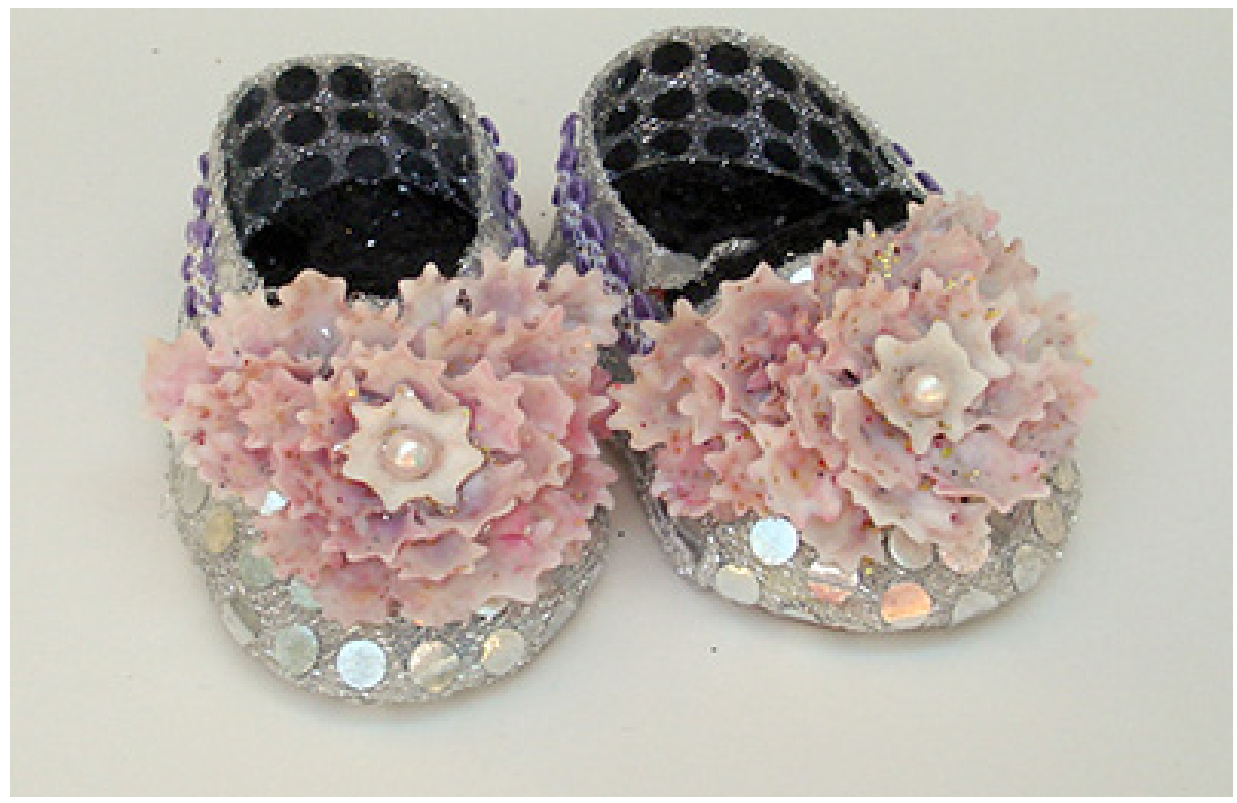

Plate 4: Marie Stewart, Disco shoes, 2006, shells, fabric and cardboard. Private collection.

Photograph: Daphne Nash.

6 Detailed analysis of the role of museums and department stores in the appropriation of Indigenous art beyond the scope of this paper. 


\section{Cultural and economic survival}

Various reasons have been given for the persistence of shell art on the South Coast. From the Aboriginal women's perspective, cultural aspects are paramount. Some Koori women believe that shell work acted as a conduit for the maintenance of other cultural practices. Art provides a context where women can assume agency through their shell work in determining cultural identity, as surviving members of Indigenous community on the South Coast with their specific relationships to kin and country. 'In communities where there is no one left to speak a language, ... visual culture is one of the most powerful mechanisms people have to express who they are and why they are here' (Bernstein 2006: 18), and on the South Coast shell art is part of Koori visual heritage.

At various points in shell art history, economic reasons were significant for the continuation of the art. In the 1980s, Gloria Ardler reminisced about watching 'her Granny' do shell work at La Perouse around the 1920s and about her mother and father who ran a little business making boomerangs and shell work and 'sold them to David Jones and sent work to Melbourne and overseas' (Australian Institute of Aboriginal Studies. 1988: 31). An image of boomerangs and shell shoes for sale at The Loop in the 1930s suggests that the shoes already had an important role and apparently shell boomerangs were also introduced around that time (Nugent 2005: 79-81). Functional items, such as milk jug covers edged by crochet work with shells attached to the ends (to weight the covers) were also popular items (before bottled milk in the 1950s). The Timbery'family's stall became a regular feature at the Royal Easter Show selling a range of artifacts including shell work Harbour Bridges, heart-shaped boxes, Good Luck horseshoes on ribbon and serving trays (see Dawn magazine 1963 12(6):9). Proximity to Sydney provided a critical mass of tourists to support a weekly stall at The Loop tram terminus, where boomerangs with burnt or painted designs were the main attraction. Together with shell work, now with an expanded range of covered objects, including Harbour Bridges, these sales 'became one of the main sources of income for local Aboriginal people and became vital to their survival' (Nugent 2005: 82-83).

As Aboriginal people came and went from La Perouse in their usual way of visiting relatives for extended periods, they spread their knowledge of shell art down the South Coast. Julie Freeman recalls that her mother brought the knowledge of shell work to Wreck Bay when she moved from La Perouse. According to Indigenous artist, Cheryl Davison, every family on the coast has links to shell work and can name an elderly aunt or grandmother who they remember working with shells. People's reminiscences suggest that the processes surrounding shell art were enjoyable social activities which included whole family groups as

7 The Timbery family are local Indigenous people with recorded associations to La Perouse from the beginnings of Sydney. 
well as resulting in significant cash for living. Esme Timbery, now over 70 years old, remembers the family trips from the days before she started school in the 1950s and 60s:

'My mother was a shell work woman. We used to catch the ferry every Monday - catch the first boat over to Kurnell. The men would walk across the sand hills to Cronulla and collect a certain kind of shell. I walked it a couple of times but it was too far - I was just a kid. The women and kids would sit at Kurnell and make some food while the men would collect 'buttons' and 'starries'. The women collected blue shells on the rocks at Kurnell - you had to boil them because they had a fish inside. We called them 'gubbens' you'd get them off the rock with a knife. There was also 'fans' - all colours, look like a fan. Men would come back and have something to eat and then we'd catch the last ferry home.'

The economic importance of shell art declined significantly by the 1970s. The closing of the tramline to La Perouse in the 1960s would have affected the numbers of visitors there. For a combination of social reasons, including employment and training opportunities elsewhere, as well as access to social welfare, Aboriginal people walked the beaches less frequently and the number of women doing shell work declined.

\section{How is shell art valued? How does it mean?}

Koori women's shell art practices have endured within several families on the South Coast. A typical narrative explanation includes its introduction by outsiders and its continuing adaptation of objects for sale (Allas 2006; Vanni 2000; Boardman and Harris 2004; Nugent 2005; Wells 2003). Within this narrative, two common themes emerge: shell art as resistance, and shell art as a form of knowledge transmission.

Framed in the post-colonial discourse of resistance, Esme's (and other shell work women in her family) use of the Sydney Harbour Bridge and other Australian icons is interpreted by some, e.g. Boardman and Harris (2004) as a political statement. From this perspective the artwork indicates the artist's rejection of the assumption that Aboriginal people around Sydney have disappeared or died out. Clearly Aboriginal people have survived and Indigenous people are aware of their political and social history as colonised peoples.

From the moment of Captain Cook's landing, understood by 'Larpa'8 people as the beginning of the invasion and their domination by outsiders, the local Aboriginal people thwarted many attempts to remove them from their land (Nugent 2005). Over the years, the production of artifacts and shell art marked their agency in resisting resettlement, a common theme in the history of blackwhite relations in the region. Both oral history and the photographic record suggest that boomerangs were the primary focus of tourist trade and Aboriginal

8 Kooris (and others) often refer to La Perouse as Larpa. 
men from La Perouse used boomerang sales for political purposes. Nugent (2005: 84) tells how when selling a boomerang to tourists, the "buyer did not only get the object itself but this local Aboriginal story of Botany Bay too' indicative of 1930 s activism. By association, shell art became the complementary women's artifact production in a resistance role.

From a cross-cultural perspective, the actions of the Aboriginal people at La Perouse who took up shell work at various times since the 1880 s can be interpreted as a clear sign of their cultural persistence in that place. Shell work, incorporating a range of activities (meeting, collecting, making and selling) was interspersed within other established social and cultural activities within a changing wider Australian society. Aboriginal people were able to add value to their local knowledge by entering the tourist trade and thereby the cash economy.

Both art commentators and the artists themselves see shell art as a vehicle for inter- generational transmission of knowledge, emphasising both the process of passing down knowledge and the nature of the practical and technical knowledge. 'This continuous tradition has ensured the survival of cultural integrity, since the making and selling of boomerangs and shell-works involves the handing down from generation to generation of both technical knowledge necessary to the craft and the design, and the knowledge of the bush, the beaches, and seasonal cycles' (Vanni 2000: 402). Sometimes a stronger ideological framework is evident. Shell artist, Joyce Donavon, wrote on her display at a Sydney conference in 2007: 'Shell work belongs to Aboriginal people from La Perouse to the far south coast. As saltwater people this craft has been handed down from our mums, grandmothers and aunts'. Her works have been predominantly red, black and yellow, and so by association with colours of the Aboriginal flag (in circulation since the early 1970s), they necessarily convey a political meaning (Plate 5).

Not all Koori shell artists view their work politically and recognise that not everyone learns the art from a close relative of a previous generation. There are other forms of knowledge transfer apart from intergenerational transmission. Through the decline in shell work activity in the second half of the twentieth century, the lines of knowledge transmission were disrupted for shell knowledge, as for all aspects of cultural knowledge. 


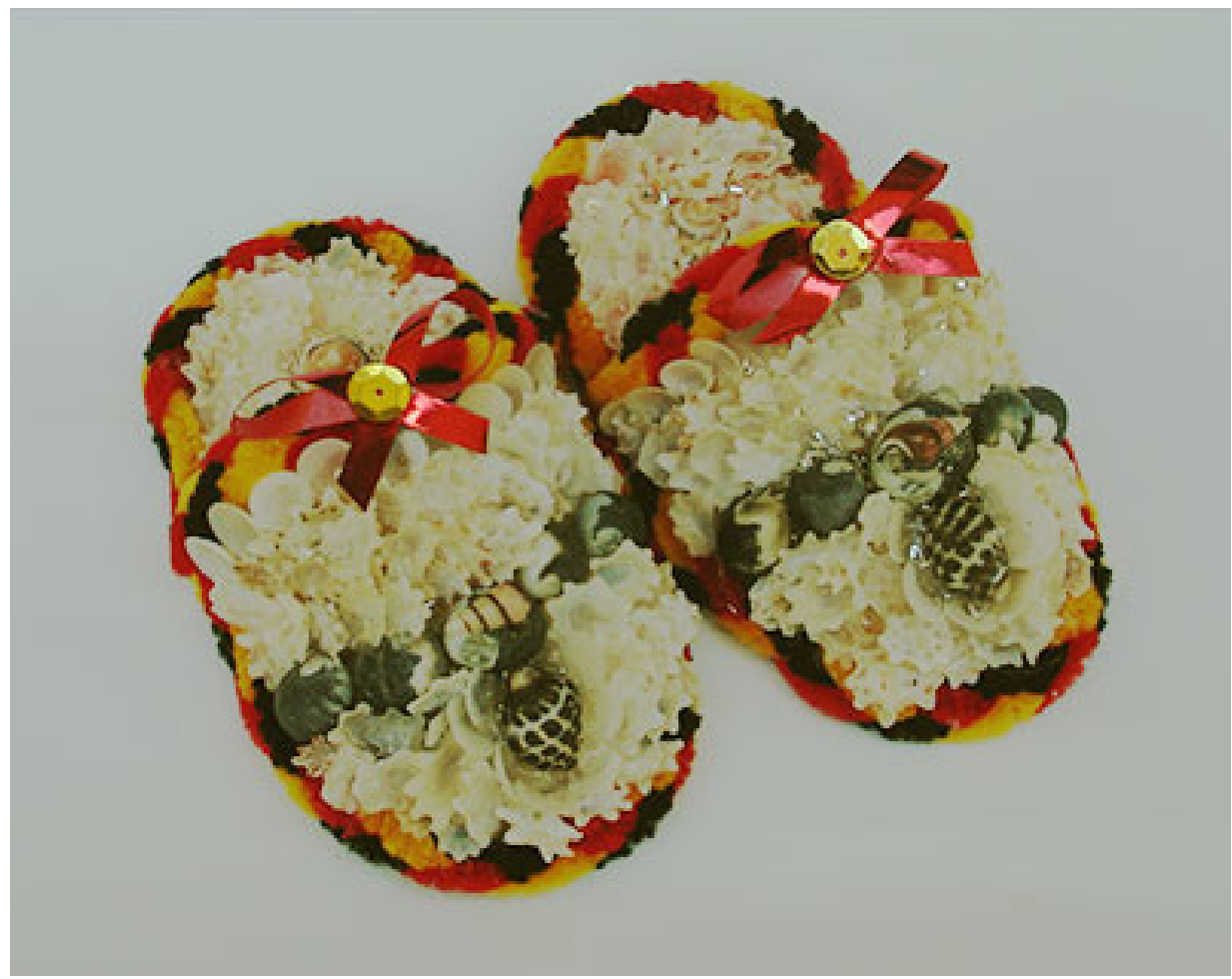

Plate 5: Joyce Donavon, Shell slippers, 2007, shells, fabric and cardboard. Private collection.

Photograph: Daphne Nash.

\section{Shell workshop}

A revival is underway in certain places on the South Coast where individual Koori women have taken action to reintroduce shell art into their community. Local Indigenous artist, Cheryl Davison organised a shell workshop at the Umbarra Cultural Centre at Wallaga Lake on the Far South Coast during the last weekend in May 2008. More than twelve other Indigenous women from various places on the South Coast came together to share ideas about shelling, through the leadership of South Coast elder Marie Stewart, a prolific shell worker over the last fifteen years (Plate 6). Marie is best known for her miniature shell shoes. 


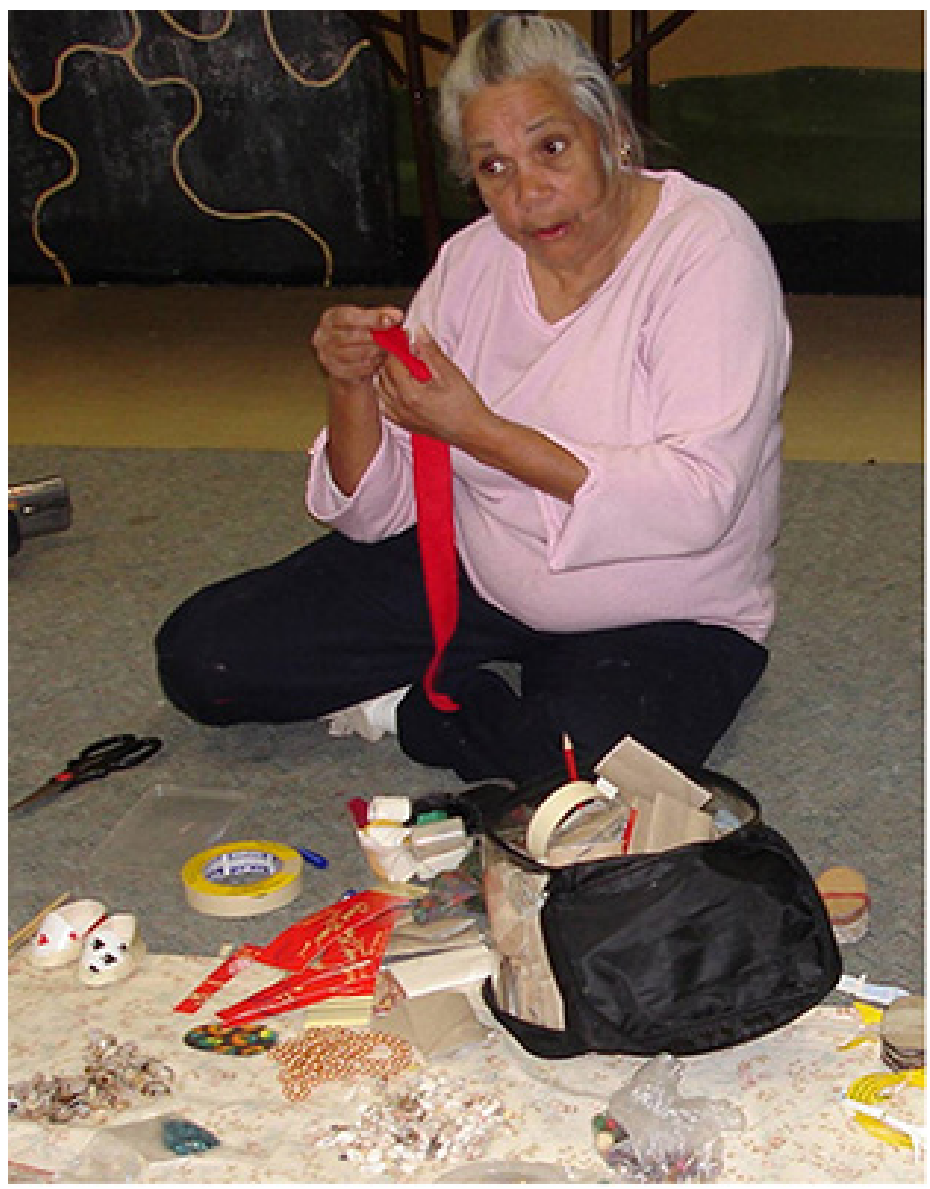

Plate 6: Marie Stewart leads the workshop at Wallaga Lake, 2008.

Photograph: Daphne Nash.

Throughout the workshop, it became clear that the making of art in shell shoes is a cultural act: from the Welcome to Country and the re-enactment of social relationships of the women gathered together, to the collection of shells and other materials, as well as the construction, design, distribution and sales.

Collecting: According to oral history, shell collecting on the South Coast continues in much the same way as it has done for over one hundred years. It was often an activity for the women and children, but large family groups would get involved for many purposes. Even today, people swim, fish, collect bait or wood, or simply spend time in the beach zone, sitting on the sand, sharing memories and reinforcing connections to these places. As Phyllis Stewart remarked:

'You need a mob with you when you go shelling. You can always find a use for every piece of shell so you're always thinking how you can use different bits - even for the broken bits.' 
The women have names for particular shells and these can vary between groups. ${ }^{9}$ Once collected, the women sort and store their shells ready for use (Plate 7).

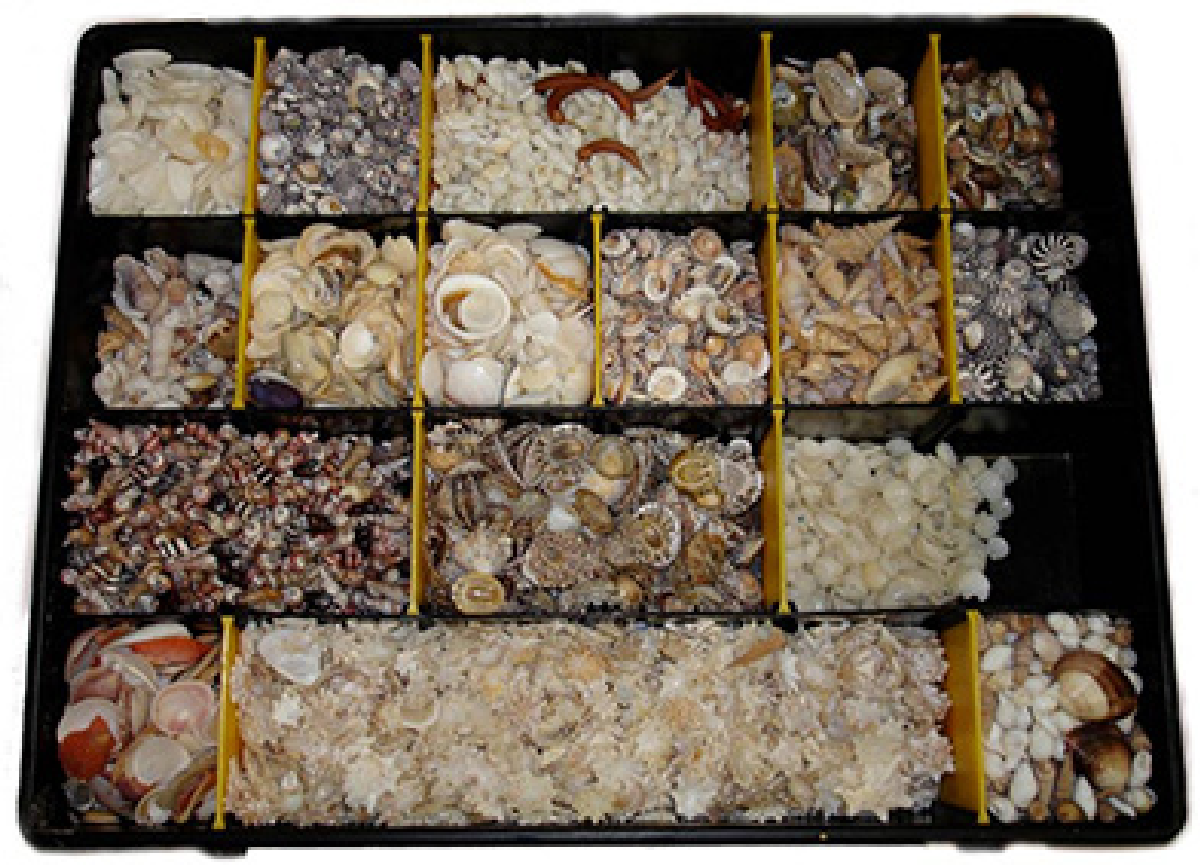

Plate 7: Wallaga Lake Workshop, Phyllis Stewart's box of shells, 2008.

Photograph: Daphne Nash.

Shoe construction: Tiny hand-crafted shoes are the most popular item for shelling today and each shell worker has her own shell shoe design. At the workshop, elder Marie Stewart demonstrated her knowledge and techniques. She developed her own style based on accessible and affordable materials including recycled toilet paper rolls and playing cards: 'You can walk into any Koori house and they've got a pack of cards. You can go through up to half a dozen packs in a night!' Being a game of chance, 'cards' is surrounded by invocations of luck and Kooris readily attribute a run of bad luck to a deck of cards. They will not hesitate to change them in an effort to turn their luck. This practice guarantees a supply is available for other purposes (Plate 8).

9 Further study of the origin and distribution of the names is underway but not included here. In brief, many names have been in use for some time and relate to everyday objects. Some have connections beyond the South Coast. 


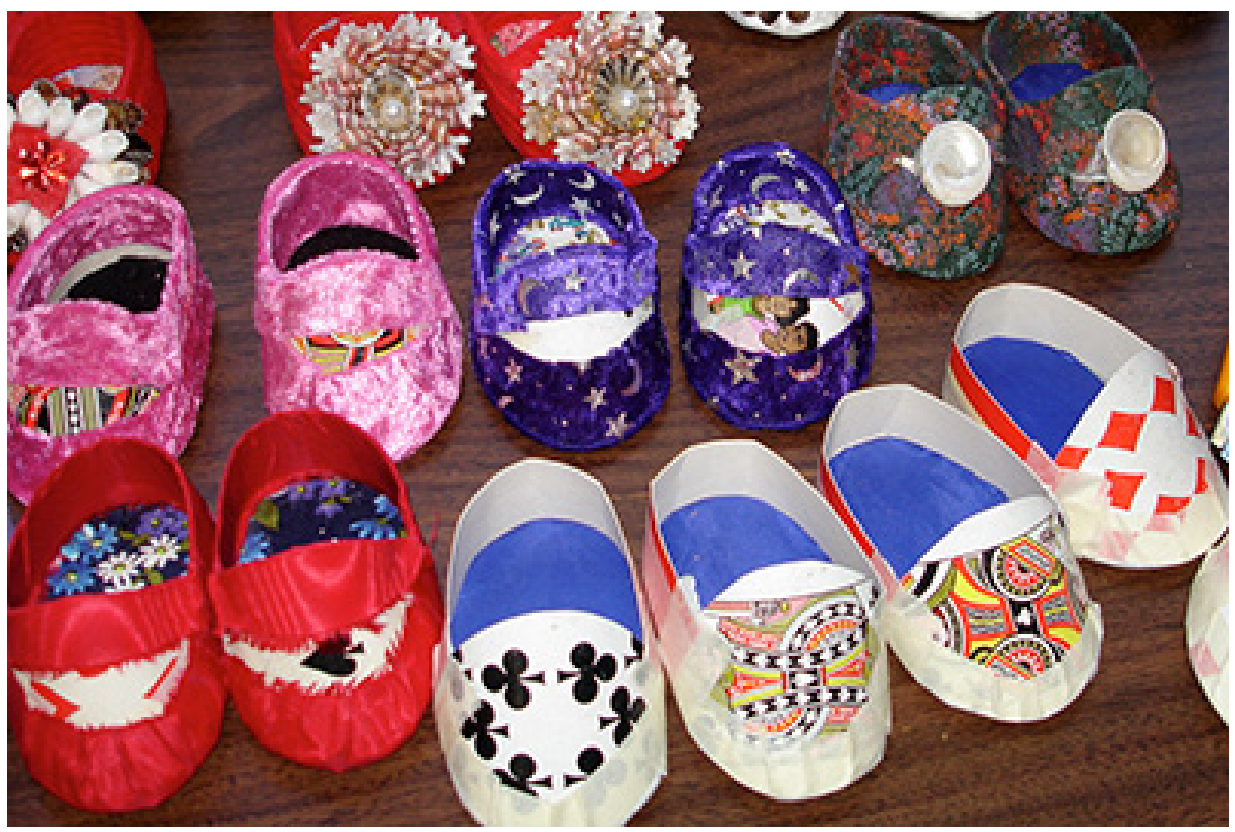

Plate 8: Marie Stewart, Shell shoes under construction, 2008.

Photograph: Daphne Nash.

Although the overwhelming motivation for shell art is the pleasure of meeting and making, the women compete to a certain degree in their exploration of a signature style. Individual pride and sense of achievement are significant as well as a desire to be distinctive in their work in order to stand out and be noticed. The women have their own style for making and shelling shoes and even without taking the shoe apart it is possible to identify the maker. As Indigenous curator, Tess Allas explains, '[e]ach artist has their own imprint ... you know that's Phyllis, that's an Esme, you know that's a Simms' (Pakula 2007). Although not explored here, the clue to identification is in the choice of shoe style, shells, shell coverage, the juxta-positioning of shells and their arrangement on the shoe, e.g. Phyllis Stewart favours a layered effect using 'buttonies' (Plate 9). ${ }^{10}$

Colour is an important visual component of the shell shoes. Over the last decade or so, the colours are brighter, due to the increased availability of reasonably priced, mostly imported fabrics and decorative accessories, such as buttons and flowers. Brightness and texture too are integral to the overall effect of each object. Esme Timbery's signature work of 'starries' and glitter ensures a 'mesmerizing and whimsical effect' (Allas 2006: 26). This is not accidental or capricious but a mimetic device. The women deliberately use some kind of

10 'Buttonies' identified as Ungulinidae in discussion with John Healy, Curator of Marine Invertebrates, Queensland Museum. 
shiny material in all their shell work to attract attention and mark their difference from the older, plainer style as they remember it, and to imitate the brightness and sparkle of the sea and its surrounds.

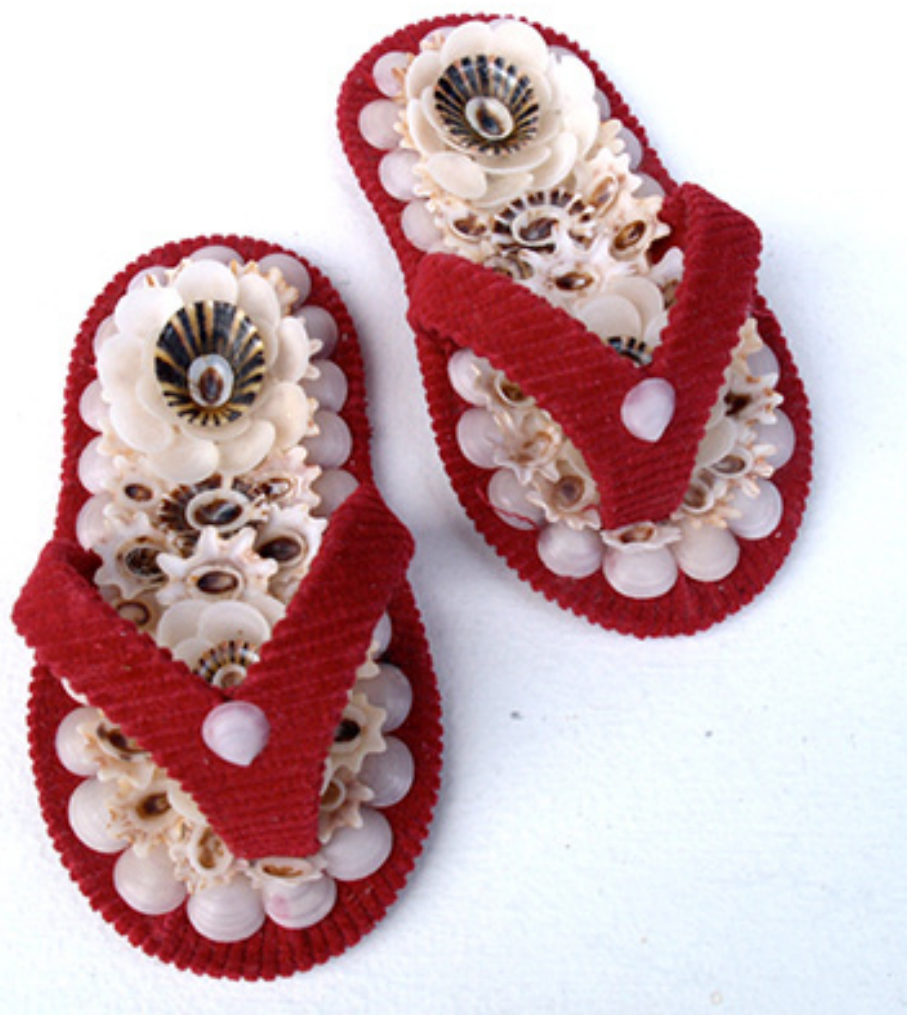

Plate 9: Phyllis Stewart, Shell thongs, 2007. Collection of the artist.

Photograph: Kelli Ryan.

It is not certain whether the original shell shoes were styled on babies' booties or miniature adult shoes. Older women today refer to the shoes as 'slippers' and 'booties' while the younger ones use the term 'shoes', a reflection of their preferred designs. The proportions of the early shell shoe shape suggest a doll's or baby's bootie and may have been used for ease and simplicity in construction. Most toe-piece decorations are made with mixed-media built on a floral design. The women make flowers with the shells, usually stylised versions or close copies of exotic, garden varieties, such as pansies made from four shell pieces to create the pansy 'face', or use a fabric flower. The shoe form (including decoration) has been fairly constant until recently when a range of modern shoe styles has appeared but with similar 'baby shoe' dimensions. The miniature flip- flops, thongs, high-heels, platforms and canvas sport shoes are all adult women's shoe styles, but mostly in 'baby shoe' proportions. 


\section{Knowledge production}

Koori women's shell objects made for sale have not changed markedly from the beginnings until the present day, which suggests continuing social and cultural motivations. Many older shell art ideas and forms have been passed on, maintaining some specific knowledge such as where to go to collect certain shells. While the missionaries were directing Aboriginal women towards the idea of appropriate work on European gender lines, they failed to understand that occupations such as shell work allowed the meeting of women in ways that strengthened traditions. In this context, 'collective forms of personhood took precedence over the individual, hence allowing for the persistence of tradition, and the evasion of control in the pursuit of Aboriginal objectives' (Lydon 2005: 212).

Consistent with this view, Indigenous artist Julie Freeman believes that shell work owes its longevity to the specific cultural practice of gathering. During the time when other activities were suppressed by the mission authorities they apparently 'didn't interfere in anyway with the women and children going to the beach. ... They had talks and told stories ... about the character of the ocean ... which wind brings what shells ... Traditional knowledge was imparted from the mums to the kids ... A whole history goes with shell work and that tradition kept all other things alive as well' (Pallingjang saltwater: Aboriginal artists of the Illawarra \& South Coast regions of New South Wales 1997: 8).

\section{Shells and sales}

Following the introduction of shell art to the Aboriginal women of Sydney in the 1880 s, they had various economic, social and cultural reasons for maintaining the practice. Each shell-covered object took relatively little time to make, especially compared to traditional necklaces such as kangaroo tooth necklace on a fibre string or a necklace from 'beachies' (with which they may not have been familiar). Materials for shell art were cheap and available. Shells could be collected readily from nearby beaches and small amounts of cardboard and fabric could be easily sourced from recycling house- hold objects, cardboard being the main packaging material of that era. There was no competing use for the finished object, so it could be kept for sale. The work could be done at home with other women, and the products could be converted to cash, probably the original appeal. Also successful relationships with the missionary workers in the early years would have contributed to the appeal of the work for some people who became active Christians themselves.

The success of shell art resonates with Indigenous people's art practices in other places. When the women at La Perouse began shelling, tourism was becoming an increasingly worldwide phenomenon where Indigenous societies were engaging in cross-cultural communication through their art. As discussed, the appeal of the miniature is a factor in the sales of the shelled objects. In other 
parts of the world 'during the twentieth century, ... artists increasingly made smaller or simpler versions of traditional objects' (Bernstein 2006: 17). Although there are no traditional equivalents of shell art in south- eastern Aboriginal culture, the shelled objects fitted into the miniature tourist art category of the times. This appeal continues today.

\section{Value creation}

In some ways, the nature and status of shell art is tied to both local and global processes. Morphy (2007) identifies three areas of the value creation process that are significant to the status of Indigenous art generally: the global art market, the Australian Indigenous art context, and Aboriginal community participation. Over the last thirty years or more, various forces within these arenas have promoted much Aboriginal art to the category of Fine Art. Shell art is no exception.

A rise in market price for shell art over the last few years suggests that the value creation process is taking positive effect. The price of shell art is not regulated in any way and depends to some extent on the sales strategies, i.e. person to person or through a commercial outlet. Increasing public exposure and recognition through the art industry, particularly the NSW Parliament Indigenous Art Prize 2005 has increased shell art's monetary value. Around that time, a pair of shell shoes retailed for about $\$ 20.00 .{ }^{11}$ In 2006 , women were amazed when they sold shoes for $\$ 75.00$ at an exhibition during the handback of Biamanga/ Gulaga National Parks. In June 2009, a pair sold for $\$ 140.00$ at a gallery in Sydney.

For the artists, sales are not always paramount. The women get satisfaction from collecting their own work as well as selling. Price is largely dependent on point of sale. On most occasions where the works were for sale, the women have commented that they were interested to display their work and get feedback but did not really mind if anything sold. Suzanne Stewart who has been shelling for some time, said in 2008: 'I keep my things, I don't sell them - they're packed away.' Since then, however, Suzanne has begun to sell some of her work. After winning the art prize in 2005, Esme Timbery's work has sold well (with increasingly higher prices), but her supply of shell works, especially the larger objects, has not kept pace with demand. Timbery began exhibiting in 1997 and with the help of Indigenous curator, Tess Allas (2007), has exhibited periodically in Sydney a few times, gradually building her reputation. At Birrung Gallery in William St, Sydney in 2007 for example, the gallery manager (pers. comm. 10 July 2007) stated: 'We can't keep up with the orders, since the TV Show. ${ }^{12}$ her son cut an opera house and she shelled it and it sold within hours

11 Prices in $\$$ A.

12 A few weeks previously (10 April 2007), ABC TV showed a documentary 'She Sells Seashells', featuring Esme Timbery. 
of being in the gallery.' To achieve a sustainable enterprise, the women would need to produce much more and sell through galleries. At this time they reject the idea of mass production and prefer the local outlets.

Sustainability is an open-ended question at this time. Even with the bold and positive initiatives of Indigenous curators and others who understand the cultural significance of the work, the future of shell art is not assured. Shell art has a long history of value within the Koori community and over the last few years is enjoying a revival, publicly and in some families. However, the practice may not be particularly robust. Without sustained and expanded effort at both community and institutional levels, it is likely that even fewer women will be making shell art after the older women stop producing. Until very recently, Esme Timbery was considered to be the last woman at La Perouse still shelling. ${ }^{13}$

Indigenous art curator, Djon Mundine ${ }^{14}$ admits that it is unfathomable as to why shell artists do not make more work for sale, given that the market is receptive and the Indigenous community values the practice in various ways. The answer may lie in one particular area of the value creation process relating to the way in which Kooris make meaning through their shell objects. The women enjoy the work and the idea that it has a Koori history. While their approach at first may appear casual and opportunistic, the artists show a resolve to be independent, in control and outside the mainstream market economy. Another important consideration is that most Koori women who are shell workers are in receipt of some kind of social welfare payment which may be jeopardised by income from sale of artwork.

Generally, Koori shell art supply and sales are sporadic, in line with production. There is no coordinated centre for production, marketing or sale on the South Coast (although typically objects are available at The Loop at La Perouse on Sundays and at Laddie Timbery's Art and Craft stall at Lady Denman Museum in Huskisson). Prices are not standardised nor quality set and controlled in any centralised way. From the buyer's perspective too, sales can be problematic. The purchaser has an expectation of authenticity, i.e. that the maker is Indigenous, and even perhaps that the shells are local. In some cases the shells are not local. ${ }^{15}$ This is not necessarily an issue for the makers, however, for whom the form of the work and the experience of making a heritage object holds most significance.

The revival of North Alaskan baleen basketry (Lee 1999) presents a useful comparison. In the period 1970s-1980s, workshops were held in many places

13 This comment has been made on many occasions by Aboriginal people from the area, e.g. 10 April 2007, ABC TV documentary 'She Sells Seashells'. Transcript available at http://www.abc.net. $\mathrm{au} / \mathrm{tv} / \mathrm{messagestick/stories/s2495615.htm.}$

14 Djon Mundine, OAM is best known as concept curator of the Aboriginal Memorial installation at the National Gallery of Australia. Djon is a Bandjalang man from northern NSW and has some family connections on the South Coast.

15 For example, at times Esme Timbery has bought shells in Sydney and from a mail order service in Queensland (pers. comm. Esme Timbery, 30/5/2006) and so their origins are not always known. 
to revive Indigenous basket making practices. Following a period of dormancy after decades of prolific production and trade, communities began to revive the knowledge. Around the same period, collecting institutions in the US began buying the baskets. Their exhibition of these objects in turn educated the public and revived their interest. A similar process appears to be occurring with shell art, if a little earlier in the cycle.

\section{MCA exhibition: shell shoes and loss}

The shell art installation, 'Shell Slippers' at the 'New Acquisitions' exhibition at the Museum of Contemporary Art in Sydney in December 2008, brought a new perspective to South Coast shell art, suggesting that the meaning of shell shoes may be more complex than so far imagined by outsiders. Indigenous curator, Djon Mundine commissioned the work for a previous exhibition of Indigenous art 'Ngadhu, Ngulili, Ngeaninyagu: A Personal History of Aboriginal Art in the Premier State' (Mundine 2008). His original idea, in collaboration with the two artists, Esme Timbery and her daughter Marilyn Russell, was to display two hundred shell shoes. Only one hundred and twenty shoes were available for the exhibition. Djon's motivation in curating the shell shoes was 'to lift the reading to another level - not just kitsch' (pers comm. 11 March 2009). In keeping with his view of the role of a curator, one should never allow the artists work to go unexplained or to 'look bad'. The label of kitsch has connotations of poor quality and insignificance. Such attributes are not consistent with the knowledge of the role of shell art in the Indigenous South Coast community or with an open attitude to all Indigenous art expression. Djon was keen 'to draw out the best' in the work which may have previously been unrecognised.

Djon Mundine believes that '[m]uch art comes from a longing concerning the past' (Mundine 2008: 33) and he applies this thesis to shell art shoes. For many NSW Indigenous people, there is a pain associated with the 'loss' of children from the Stolen Generation. ${ }^{16}$ The artist Esme Timbery had a sister who was taken away. In her discussion with Mundine, it is clear that she experiences ongoing pain and loss associated with that trauma.

Djon Mundine takes the idea of loss further in that some people with deep, psychological pain choose to perform simple, routine tasks over and over again as a way of subconsciously coping with their pain. He believes that shell art may have served this purpose for the Aboriginal women of La Perouse. In particular, shell shoes with their obvious similarity in form to baby shoes focus on the loss of children and babies, a loss that many Aboriginal families can relate to. The association of the miniature form with loss and longing is also

16 'The Stolen Generations' is the term used to refer to the generations of Aboriginal children who were taken from their families as a result of Australian Government policies mainly during the period 1909-1969. 
well founded (Stewart 1993). Moreover, both the adult and baby shoe forms are highly personalised female objects and their appeal to other (white) women draws on that connection.

The shell shoes installation plays on the viewer's perceptions of repeated images. The use of 'visual redundancy' provides 'visual and textual authority' (Steiner 1999: 92, 95). In 'Shell Slippers' at the MCA, the mass display establishes the shell shoe as part of the canon of Indigenous art. In the beginning, Mundine commissioned two hundred little shoes: 'Every number has its own aesthetic and context, every figure it's own story...' (Mundine 2008: 21) and the context is the number of years of European presence in Australia. In the final installation, he achieved a critical mass of shoes and although less than two-hundred, the visual effect is strong. The viewer looks for more meaning in the configuration: the rectangular shape is flag-like but not a flag. That shoes of the same colour are grouped together keeps the viewer peering at, and through, the space, searching for a recognisable form.

Empty shoes have a resonance with other historical moments, such as in the images of shoes belonging to children who perished in the Holocaust (Feldman 2008: 124), another event deeply associated with suffering and loss. Also for modern Kooris, empty shoes denote the widespread Western, including Australian, practice in families of keeping a child's first shoe as a memento of a passing developmental phase. In the 'Shell Slippers' installation, the mass of empty shoes is both the medium and the message.

Mundine's interpretation may explain why the Aboriginal women of 'Larpa' and the South Coast have maintained the shell art practice for so long (over 120 years), although in a fairly limited way. The artists have not moved to a more intense level of production because they reject the commodification of such deeply personal associations of home and family based activities. Instead, the production and sale of shell art over more than a century is grounded in the private/domestic sphere extending beyond to an engagement with nonIndigenous people through limited exposure in exhibitions, media and sales associated with the art industry. In many ways, the artists limit their participation in the public domain by choice in order to remain in control of the processes. At the same time, they are committed to communicating through their art to a wider Australian audience about their cultural knowledge. Their strategies may not have always been understood but the impact of their actions is unambiguous. For too long, shell art has been underestimated as a visual mode of crosscultural communication about Indigenous history and knowledge on the South Coast.

\section{Conclusion}

Shell art will always be known as the activity of the Aboriginal women of La Perouse and other parts of the South Coast of NSW, but its future is unclear. 
Undoubtedly, the global art process and the Australian Indigenous art market, including tourism, will have a significant impact on how successful shell art can become. It is the Koori community, however, who will decide the extent to which this can happen. Currently the women's agency in reviving the tradition is significant. They demonstrate a breadth of culturally specific knowledge communicated in a particular visual style that maintains a resistance component. As this case study demonstrates, the revival of shell art is closely associated with opportunities for cross-cultural engagement and the processes of value creation.

\section{Bibliography}

Allas, T. 2006. Esme Timbery. Art Monthly Australia (187):24-26.

- - - 2007. Esme Timbery. http://www.daaa.org.au (accessed 10/6/2009).

Atkinson, L. 1854. Native arts No.2. The Illustrated Sydney News, 4 February, 141.

Australian Institute of Aboriginal Studies. 1988. La Perouse, the place, the people and the sea: a collection of writing by members of the Aboriginal community. Canberra: Aboriginal Studies Press for the Australian Institute of Aboriginal Studies.

Beechey, D. 2009. The seashells of New South Wales. http://seashellsofnsw. org.au/index.htm (accessed 24/6/2009).

Bernstein, B. 2006. Why create? Why collect? In Indigenous motivations: recent acquisitions from the National Museum of the American Indian, edited by National Museum of the American Indian. Washington: Smithsonian Institution, pp. 15-29.

Binkley, S. 2000. Kitsch as a repetitive system: a problem for the theory of taste hierarchy. Journal of Material Culture 5 (2):131-152.

Boardman, A., and Harris, K. 2004. Esme Timbery. Education kit "Terra Alterius: land of another", www.cofa.unsw.edu.au/export/sites/cofa/galleries/idg/.../ terra_alterius.pdf (accessed 25/4/2007).

Feldman, J. 2008. The Holocaust shoe: untying memory: shoes as Holocaust memorial experience. In Jews and shoes, edited by E. Nahson. Oxford ; New York: Berg, pp. 120-130.

Goodall, H. 1995. 'Assimilation begins at home': the state and Aboriginal women's work as mothers in New South Wales, 1900s to 1960s. Labour History 69:75-101. 
Lee, M. 1999. Tourism and taste cultures: collecting native art in Alaska at the turn of the twentieth century. In Unpacking culture: art and commodity in colonial and postcolonial worlds, edited by R. B. Phillips and C. B. Steiner. Berkeley: University of California Press, pp. 267-281.

Lydon, J. 2005. 'Our sense of beauty': visuality, space and gender on Victoria's Aboriginal Reserves, south-eastern Australia, History and Anthropology 16(2):211-233.

Mathews, R.H. 1896. The Bunan Ceremony of New South Wales. American Anthropologist 9 (10):327-344.

Moore, C. 2005. Margaret Preston at home. In Radical revisionism: an anthology of writings on Australian art, edited by R. Butler. Fortitude Valley, Qld.: Institute of Modern Art, pp. 200-212.

Morphy, H. 2007. Creating value, adding value and maintaining value: the complexity of Aboriginal art as industry. NAVA Quarterly 07 (1):10-11.

Mundine, D. 2008. Premier state: first state, first people. In Ngadhu, Ngulili, Ngeaninyagu: a personal history of Aboriginal art, edited by D. Mundine. Campbelltown, NSW: Campbelltown Arts Centre, pp. 15- 33.

Nugent, M. 2005. Botany Bay: where histories meet. Crow's Nest, NSW: Allen \& Unwin.

Organ, M. 1990. A documentary history of the Illawarra \& South Coast Aborigines 1770-1850.

Wollongong: Aboriginal Education Unit, University of Wollongong.

Pakula, K. 2007. Shells bridge the gap between kitsch and art. The Sydney Morning Herald, April 6-8, 2007, Life: 26.

Pallingjang saltwater: Aboriginal artists of the Illawarra \& South Coast regions of New South Wales. 1997. Wollongong: Wollongong City Gallery.

Parliament of New South Wales. 2005. Parliament of New South Wales Indigenous Art Prize 2005. Sydney: Parliament of New South Wales.

Phillips, R.B. 1999. "Queen of the Huron": appropriating the savage in nineteenthcentury Huron tourist art. In Unpacking culture: art and commodity in colonial and postcolonial worlds, edited by R. B. Phillips and C. B. Steiner. Berkeley: University of California Press, pp. 33-50.

Steiner, C.B. 1999. Authenticity, repetition, and the aesthetics of seriality: the work of tourist art in the age of mechanical reproduction. In Unpacking culture: art and commodity in colonial and postcolonial worlds, edited by R. B. Phillips and C. B. Steiner. Berkeley: University of California Press, pp. 87-103. 
Stewart, S. 1993. On longing: narratives of the miniature, the gigantic, the souvenir, the collection. 1st paperback ed. Durham: Duke University Press.

Sturken, M. 2007. Tourists of history: memory, kitsch, and consumerism from Oklahoma City to Ground Zero. Durham: Duke University Press.

Thomas, I. 2007. The shell: a world of decoration and ornament. London: Thames \& Hudson.

Vanni, I. 2000. Bridging the gap: the production of tourist objects at La Perouse. In The Oxford companion to Aboriginal art and culture, edited by S. Kleinert and M. Neale. Oxford: Oxford University Press, pp. 400- 402.

Walker, L. 1986. Entry of women into the architectural profession in Britain. Women's Art Journal 7 (1):13-18.

Wells, K., ed. 2003. Crossing the strait: Tasmania to the south coast. Canberra: Continental Shift Association.

Willson, A.B. 1998. Alexander Pope's grotto in Twickenham. Garden History 26 (1):31-59. 